\title{
Correction to: Occurrence and environmental risks of nonsteroidal anti-inflammatory drugs in urban wastewater in the southwest monsoon region of India
}

\author{
Arun Kumar Thalla • Adhira Shree Vannarath
}

Published online: 22 August 2020

(C) Springer Nature Switzerland AG 2020

Correction to: Environ Monit Assess (2020) 192: 193

https://doi.org/10.1007/s10661-020-8161-1

The original version of this article unfortunately published online with missing acknowledgment section.

The added acknowledgement section is shown below.

Acknowledgements Authors thank Dr. Babu Rajendran, Professor \& Head, Environmental Toxicology \& Toxicogenomics Lab, Department of Environmental Biotechnology, Bharathidasan University, Tamilnadu, India, for extending the GC-MS facility to us. Authors also thank Ms. Padmapriya Janakiraman for her help in collecting and analyzing the samples. This research did not receive any specific grant from funding agencies in the public, commercial, or not-for-profit sectors.

Publisher's note Springer Nature remains neutral with regard to jurisdictional claims in published maps and institutional affiliations.

The online version of the original article can be found at https://doi.org/10.1007/s10661-020-8161-1

A. K. Thalla $(\bowtie) \cdot$ A. S. Vannarath Department of Civil Engineering, National Institute of Technology Karnataka Surathkal, Mangalore, Karnataka 575025, India e-mail: thallpce@gmail.com 